\title{
Management of dyspeptic patients by general practitioners and specialists
}

\author{
V Stanghellini, C Tosetti, G Barbara, B Salvioli, R De Giorgio, R Corinaldesi
}

\section{Introduction}

The respective roles of general practitioners and specialists in the management of most diseases is not clearly defined and dyspepsia is no exception. Ideally, the division of tasks should be based on the characteristics of different diseases and on specific objectives.

The prevalence of dyspepsia ranges between 20 and $40 \%$ in industrialised countries and roughly $25 \%$ of patients seek medical help, whereas the remainder often self-medicate. ${ }^{1}$ Although frequently idiopathic (or functional), dyspepsia can be secondary to a variety of serious (and sometimes fatal) organic, systemic and metabolic diseases that need to be identified. Functional dyspepsia also precipitates a substantial reduction in the quality of life of affected patients with relevant costs for society. The current economic restrictions prevent referral of every patient and correct management of dyspepsia is a formidable task.

Prospective studies have been undertaken to establish the respective effectiveness of different doctors in the management of some gastroenterological diseases. Zarling et al compared the efficacy of management of acute diverticulitis provided by general practitioners, internists and gastroenterologists, and observed shorter hospital stay and lower readmission rates in patients treated by gastroenterlogists. ${ }^{2}$ Unlike acute diverticulitis, dyspepsia is a very heterogeneous condition and no similar studies are available as yet. Tackling the following questions may help to elucidate the remit of different doctors.

- What drives a dyspeptic individual to consult a physician?

- Do different doctors see different types of dyspeptic patients?

- What is the diagnostic yield of an extensive work-up by a specialist?

- Should different doctors adopt different strategies for the management of dyspepsia?

- What is the most cost-effective way to manage dyspepsia?

Department of

Internal Medicine and

Gastroenterology,

University of Bologna,

Policlinico S.

Orsola-Malpighi,

Via Massarenti 9,

I-40138 Bologna, Italy

V Stanghellini

C Tosetti

G Barbara

B Salvioli

R De Giorgio

R Corinaldesi

Correspondence to: Dr Stanghellini.

\section{What drives a dyspeptic individual to consult a physician?}

As previously mentioned, roughly $75 \%$ of subjects with dyspeptic symptoms never consult a doctor for this specific problem. ${ }^{1}$ There are two main reasons why the remainder seek medical help: the severity of their clinical condition ${ }^{3-5}$; and fear of underlying serious disease. ${ }^{16}$ Frexinos et al have recently reported on the largest study in this field. ${ }^{7}$ An ad hoc questionnaire was mailed to 4817 subjects randomly sampled from the French population, with a response rate of $80 \%$. The factors associated with consultation were: duration of symptoms, frequency of symptoms, presence of pain, age 65 years or older, presumed organic origin, lack of presumed alimentary intolerance. Doctors should investigate the reason for referral carefully as it obviously influences patients' behaviour and expectations.

\section{Do different doctors see different} dyspeptic patients?

Although most dyspeptic patients who seek medical help in industrialised countries are seen by general practitioners (GPs), most of the information available in the literature is from patients investigated at referral centres. The extent to which these data can be extrapolated to all dyspeptic patients is not clear. In neurology, specialists see younger and healthier patients than GPs. ${ }^{8}$ The latter probably see chronic forms of disease after a diagnosis has been established. In other disciplines, specialists seem to see older and sicker patients than family doctors. ${ }^{9}$ Few such data exist on dyspeptic patients. Adang and colleagues ${ }^{10}$ described demographics, clinical features, endoscopic indications and findings in 2900 patients referred for endoscopy by GPs (42\%) and specialists (58\%). They concluded that specialists generally refer older patients with secondary dyspepsia, whereas GPs more frequently refer patients with idiopathic dyspepsia. Other relevant differences between the two groups were: over $80 \%$ of patients referred by GPs complained of pain, which was not the case in patients referred by specialists; ulcer healing therapy had been prescribed to over half the patients referred by GPs, and to only a quarter of those referred by specialists. Endoscopic diagnosis in open access units and clinics also differs. ${ }^{11}$ In open access endoscopy units almost $40 \%$ of patients were under 45 years of age, whereas in the latter over 30\% were over 70 . As a consequence of the age distribution, significantly more malignancies were detected in the clinic group. Recent preliminary data ${ }^{12}$ fail to corroborate these findings and found no differences in endoscopic findings in patients managed by GPs or specialists. It is likely that the type of dyspeptic patients seen by family doctors and specialists in different countries varies according to the different health care systems in use.

What is the diagnostic yield of an extensive work-up by a specialist?

Traditional diagnostic tests often fail to identify any recognisable disease in dyspeptic patients, whereas sophisticated pathophysiological tests can disclose abnormalities in a large proportion of patients with otherwise unexplained dyspepsia. Although a causal link 
between pathophysiological abnormalities and symptoms has not been fully established, identification of an underlying functional disorder can direct treatment appropriately in some specific conditions such as gastro-oesophageal reflux disease. However, sophisticated tests are generally available in dedicated referral centres and their use and diagnostic potential is often overlooked by GPs. Klauser and colleagues ${ }^{13}$ specifically evaluated the diagnostic yield of an extensive work-up in over 200 patients with previously uninvestigated dyspepsia. Organic disease was detected in $40 \%$ of the patients using a conventional work-up comprising endoscopic, radiological and ultrasonographic examination. Roughly 100 patients with functional dyspepsia were then investigated using other tests, including lactose tolerance, oesophageal pH-metry, oesophageal manometry, and scintigraphic studies of oesophageal transit, gastric emptying and duodenogastric reflux. A potential cause of symptoms was detected in $47 \%$ of patients using these tests. Whether extensive work-ups lead to improved and cost-effective management of patients should be explored in future studies.

\section{Should different doctors adopt different strategies for the management of dyspepsia?}

In the pre-Helicobacter pylori era, management of dyspeptic patients strongly relied upon upper gastrointestinal endoscopy and was therefore largely in the remit of specialists. Prompt endoscopy had been shown to be more cost-effective than empirical antisecretory therapy by reducing the number of visits to GPs and dyspepsia related sick leave over the first year of follow up. ${ }^{14}$ Endoscopy is certainly recommended in patients with alarming features, such as the onset of symptoms after 40-45 years of age, anaemia, blood loss, anorexia, weight loss, recurrent vomiting, and progressive dysphagia. ${ }^{15}$ Several guidelines $^{16}$ on the appropriateness of endoscopy have been proposed by panels of experts both in North America $^{17-19}$ and in Europe. ${ }^{12} 20$ Prospective evaluation of the prescribing attitudes of GPs in the light of these official recommendations has generally led to unsatisfactory results. ${ }^{121-24}$

The recent recognition of $H$ pylori as a major gastroduodenal pathogen and the availability of non-invasive techniques for establishing $H$ pylori status have had a considerable effect on the management of dyspepsia. In a prospective study, Patel et al evaluated the value of recording a patient's medical history and serological $H$ pylori testing in the management of young dyspeptic patients. ${ }^{25}$ Only those with positive serology or alarming features, or both, underwent endoscopy. All patients received an explanation of the nature of their symptoms and returned to the primary care physicians for treatment of their ulcer or symptoms, or both. Almost $40 \%$ of endoscopies were avoided and the use of medication was lower compared with the pre-screening period. Only $4 \%$ of $H$ pylori negative patients underwent endoscopy at a later date. This figure is notably lower than that reported in series in which no $H$ pylori testing was undertaken, ${ }^{14}$ probably because of the reassurance offered through clear explanation of the low risk of serious disease in young uninfected subjects. This hypothesis is also supported by recent preliminary reports. ${ }^{26} 27$ Taken together these data suggest that GPs and specialists have different roles in the management of dyspepsia. Young dyspeptics without alarming features should be tested for $H$ pylori using a non-invasive test and, if positive, should be treated directly, provided that their family doctors have access to reliable non-invasive $H$ pylori testing and have sufficient experience of eradication therapies. Older patients, or patients with alarming features, or nonresponders to therapy should be referred to a specialist and investigated carefully. A similar approach has been proposed in a recent consensus report from the European Helicobacter pylori Study Group. ${ }^{28}$ Education on appropriate $H$ pylori testing and treatment is mandatory given the current tendency to eradicate $H$ pylori in all infected subjects who seek medical help and given that the vast majority of $H$ pylori related conditions are treated by GPs. Inappropriate overprescription of antibiotics would add further to the already serious problem of antibiotic resistance ${ }^{29}$ among $H$ pylori, other potential pathogens, and the normal flora.

\section{What is the most cost-effective way to manage dyspepsia?}

Despite the numerous strategies proposed in literature for the management of dyspepsia many uncertainties remain, and the general impression is that confusion reigns. Theoretical decision analysis studies have been undertaken recently to explore the cost-effectiveness of competing strategies for the management of dyspeptic patients. Silverstein et al compared the direct medical costs in the first year after the onset of dyspepsia for patients managed by initial endoscopy or empirical therapy with $\mathrm{H}_{2}$ receptor antagonists with or without noninvasive testing for $\mathrm{H}$ pylori..$^{30}$ Surprisingly, no substantial difference was found among the different strategies. Briggs et al calculated that a marginal economic advantage of $H$ pylori eradication over more traditional strategies could be expected only after roughly 10 years. ${ }^{31}$ These theoretical exercises cannot provide sufficient answers given the complexity of this issue, which should be tackled by appropriate prospective studies. For the time being common sense and experience should guide all doctors in the management of their dyspeptic patients.

As previously mentioned, there are two types of dyspeptic patients: those who fear a serious cause of their symptoms ${ }^{16}$ and those who are bothered by their symptoms. ${ }^{3-5}$ It is likely that if appropriately investigated by dedicated physicians the patients can clearly express their perceptions and worries and this will become an important aspect of future management. Those who fear that they have cancer should be promptly referred to the specialist for a thorough investigation including endoscopy, as reassurance based on favourable probabilities 
will not prevent expensive and time-consuming "doctor shopping". Other patients are simply worried as they do not understand the nature of their symptoms. In this group a non-invasive test performed by the family doctor to assess $H$ pylori status is probably sufficient. ${ }^{25-27}$ Other subjects would never consult a doctor unless disturbed by the severity of their symptoms. In the absence of any alarming features, the most cost-effective way to manage these cases is effective control of their symptoms. Finally, as previously stated, advancing age, alarming clinical features, and frequent recurrence after treatment should prompt appropriate investigation in all cases.

In the near future, large scale, well conducted trials will clarify the role of $H$ pylori infection in dyspepsia and increase doctors knowledge and confidence in this field. Endoscopy will be reserved for those who do not respond to symptom treatment or in whom symptoms recur more than three or four times a year. Close collaboration between family doctors and specialists, with frequent exchange of information, is essential for appropriate management of dyspepsia.

1 Jones R, Lydeard S. Prevalence of symptoms of dyspepsia in the community. BMF 1989;298:30-2

2 Zarling EJ, Piontek F, Klemka-Walden L, et al. The effect of gastroenterology training on the efficiency and cost of care provided to patients with diverticulitis. Gastroenterology 1997;112:1859-62

3 Holtman G, Goebell H, Talley NJ. Dyspepsia in consulters and non-consulters: prevalence, health care seeking behaviour and risk factors. Eur $\mathcal{F}$ Gastroenterol Hepatol 1994;6: 917-24.

4 Shaw MJ, Beebe L, Adlis S, et al. Dyspepsia: comparison of community and clinic populations [abstract]. Gastroenterology 1996;110:A38.

5 Talley NJ, Boyce P, Jones M. Symptoms but not psychological factors predict health care seeking in subjects with irritable bowel syndrome and dyspepsia: a population-based study [abstract]. Gastroenterology 1997;112:A835.

$6 \mathrm{Hu}$ WHC, Hui WM, Lam CLK, et al. Anxiety and depression are cofactors determining health care utilization in patients with dyspepsia [abstract]. Gastroenterology 1997; 112:A153.

7 Frexinos J, Allemand $\mathrm{H}$, Allouche S, et al. Descriptive study of functional digestive symptoms in the French general of functional digestive symptoms in the French gen

population [abstract]. Gastroenterology 1997;112:A733.
8 Horner RD, Matchar DB, Divine GW, et al. Relationship between physician specialty and the selection and the outbetween physician specialty and the selection and the out-
come of ischemic stroke patients. Health Serv Res 1995;30:

9 Greenfield S, Nelson EC, Zubcoff M, et al. Variations in resource utilization among medical specialties and system of care. $\mathcal{F A M A} 1992 ; 267: 1624-30$
10 Adang RP, Vismans JFJFE, Talmon JL, et al. The diagnostic outcome of upper gastrointestinal endoscopy: are referral source and patient age determining
Gastroenterol Hepatol 1994;6:329-35.

11 Kerrigan DD, Brown SR, Hutchinson GH. Open access gastroscopy: too much to swallow? BMF 1990;300:374-6.

12 Froelich F, Pache I, Burnand B, et al. Underutilization of upper gastrointestinal endoscopy. Gastroenterology 1997; 112:690-7.

13 Klauser AG, Voderholzer WA, Knesewitsch PA, et al. What is behind dyspepsia? Dig Dis Sci 1993;38:147-54.

14 Bytzer P, Hansen JM, Schaffalitzky de Muckadell OB. Empirical $\mathrm{H}_{2}$-blocker therapy or prompt endoscopy in
management of dyspepsia. Lancet 1994;343:811-16.

15 American College of Physicians. Endoscopy in the evaluation of dyspepsia. Ann Intern Med 1985;102:266-9.

16 Axon ATR. Chronic dyspepsia: who needs endoscopy? Gastroenterology 1997;112:1376-80.

$17 \mathrm{Kahn} \mathrm{KL}$, Roth CP, Kosecoff J, et al. Indications for selected medical and surgical procedures. A literature review and ratings of appropriateness. Diagnostic upper gastrointestinal endoscopy. RAND publication no R-3204/4-CWP/HF/ HCFA/PMT/RWJ. Santa Monica, CA: RAND Corporation, 1986.

18 American Society for Gastrointestinal Endoscopy. Guidelines for clinical application. Gastrointest Endosc 1988; 34(suppl): 4-25S.

19 American Society for Gastrointestinal Endoscopy. Appropriate use of gastrointestinal endoscopy. Manchester, MA American Society for Gastrointestinal Endoscopy, 1989

20 Quine MA, Bell GD, McCloy RF, et al. Appropriate use of upper gastrointestinal endoscopy - a prospective audit. Gut 1994;25:1209-14

21 Kahn KL, Kosecoff J, Chassin MR, et al. The use and misuse of upper gastrointestinal endoscopy. Ann Intern Med 1988;109:664-70.

22 Naji SA, Brunt PW, Hagen S, et al. Improving the selection of patients for upper gastrointestinal endoscopy. Gut 1993; 34:187-91.

23 Minoli G, Prada A, Gambetta G, et al. The ASGE guidelines for the appropriate use of upper gastrointestinal endoscopy in an open-access system. Gastrointest Endosc 1995;42:387-9.

24 Gonvers JJ, Burnand B, Froelich F, et al. Appropriateness and diagnostic yield of upper gastrointestinal endoscopy in a open-access endoscopy unit. Endoscopy 1996;28:661-6.

25 Patel P, Khulusi S, Mendall MA, et al. Prospective screening of dyspeptic patients by Helicobacter pylori serology. Lancet 1995;346:1315-18.

26 Fraser AG, McIntosh C, Berry S, et al. The urea breath test (UBT) for H. pylori (HP) in the initial assessment of dyspepsia in primary care [abstract]. Gut 1997;41:A77-8.

27 Heaney A, Collins JSA, Tham TCK, et al. A prospective study of $\mathrm{H}$. pylori negative dyspeptics. Can gastroscopies be saved in clinical practice [abstract]? Gut 1997;41 A93-4.

28 The European Helicobacter Pylori Study Group. Current European concepts in the management of Helicobacter pylori infection. The Maastricht Consensus Report. Gut 1997; $41: 8-13$.

$29 \mathrm{Neu} \mathrm{HC}$. The crisis in antibiotic resistance. Science 1992;257:1064-73.

30 Silverstein MD, Petterson T, Talley NJ. Initial endoscopy or empirical therapy with or without testing for Helicobacter pylori for dyspepsia: a decision analysis. Gastroenterology 1996;110:72-83.

31 Briggs AH, Sculpher MJ, Logan RPH, et al. Cost effectiveness of screening for and eradication of Helicobacter pylori in management of dyspeptic patients under 45 years of age. BMF 1996;312:1321-5. 